\title{
A CONTRIBUIÇÃO DAS ÁREAS VERDES PARA O BEM-ESTAR E SAÚDE AMBIENTAL NO AMBIENTE ESCOLAR
}

\section{THE CONTRIBUTION OF GREEN AREAS TO WELL-BEING AND ENVIRONMENTAL} HEALTH IN THE SCHOOL ENVIRONMENT

Gilivã Antonio Fridrich ${ }^{1^{*}}$

\section{Resumo}

A dimensão afetiva, perceptiva e representativa na relação entre os humanos e o meio ambiente é altamente reconhecida como partícipe importante na compreensão do compromisso ambiental. Um ambiente com espaços verdes catalisa maior interação entre humanos e natureza. A temática sobre áreas verdes é complexa, permitindo vários olhares e perspectivas de análise. Neste estudo, procurou-se dar ênfase e tecer reflexões acerca dos benefícios de saúde que são proporcionados pelas áreas verdes no espaço escolar e suas contribuições para a qualidade de vida da população estudantil. 0 estudo teve como objetivo central, verificar os benefícios que os espaços verdes inseridos nos ambientes escolares contribuem para o sistema educacional, o bem-estar e saúde dos estudantes. A metodologia deu-se por meio de análise observacional e de estruturas e organização dos espaços de quatro escolas (duas centrais e duas periféricas) de João Pessoa (PB). Nesses locais, foram observados se havia uma composição florística bem como, sua aproximação junto aos estudantes. No ambiente educacional esses espaços, são essenciais para as práticas de ensino, contribuindo para a qualidade de vida dos educandos. Constatou-se que as escolas centrais apresentam poucos espaços verdes, remetendo-se em poucas árvores, jardins e arbustos, se comparado com escolas mais periféricas, com uma organização florística maior, sustentável e contato direto com os estudantes, visualizando uma melhoria no desempenho escolar e bem-estar humano. Destacamos que a natureza precisa estar presente na organização espacial e/ou no cotidiano das escolas, pois é compreendida como um espaço potencial para o desenvolvimento equilibrado dos estudantes. Esses espaços

\section{Abstract}

The affective, perceptive and representative dimension in the relationship between humans and the environment is highly recognized as an important participant in understanding environmental commitment. An environment with green spaces catalyzes greater interaction between humans and nature. The thematic about green areas is complex, allowing various perspectives and perspectives of analysis. In this study, we sought to emphasize and weave reflections on the health benefits that are provided by green areas in the school space and their contributions to the quality of life of the student population. The study aimed to verify the benefits that the green spaces inserted in the school environments contribute to the educational system, the well-being and health of the students. The methodology was done through observational analysis and structures and organization of the spaces of four schools (two central and two peripheral) in João Pessoa (PB). In these places, it was observed if there was a floristic composition as well as its approach with the students. In the educational environment these spaces are essential for teaching practices, contributing to the quality of life of students. It was found that the central schools have few green spaces, referring to few trees, gardens and shrubs, compared to more peripheral schools, with a larger, sustainable floristic organization and direct contact with students, visualizing an improvement in school performance. and human welfare. We emphasize that nature needs to be present in the spatial organization and / or in the daily life of schools, as it is understood as a potential space for the balanced development of students. These spaces need to be more worked because they represent a great
1 Doutor em Desenvolvimento e Meio Ambiente; Mestre em Saúde e Meio Ambiente; Biólogo.

precisam ser mais trabalhados, pois representam um recurso grandioso para a socialização e melhoria na qualidade de vida, além de possibilitar melhor desempenho nos estudantes. Por desempenharem diferentes funções as áreas verdes proporcionam inúmeros benefícios tanto para a qualidade do meio ambiente trazendo um equilíbrio ambiental, quanto para saúde e bem-estar no ambiente educacional. Estudos que investiguem a relação de áreas verdes e saúde em centros urbanos em especial os ambientes educacionais são extremamente necessários, e podem contribuir na formação de políticas públicas que norteiem práticas sustentáveis e de melhorias na condição da saúde da população.

Palavras-chave: Áreas Verdes. Qualidade de Vida. Saúde. Ambiente escolar.

resource for socialization and improvement in quality of life, and enable better performance in students. By performing different functions, green areas provide numerous benefits both for the quality of the environment bringing an environmental balance, as well as for health and well-being in the educational environment. Studies that investigate the relationship of green areas and health in urban centers, especially educational environments, are extremely necessary, and may contribute to the formation of public policies that guide sustainable practices and improvements in the health condition of the population.

Keywords: Green areas. Quality of life. Health. School environment.
Recebido em: 27 Oct. 2021

Aceito em: 29 Nov. 2021

Publicado em: 30 Dez. 2021

(c) Copyright 2021

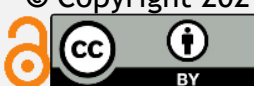

Fridrich, G. A. 


\section{Resumen}

La dimensión afectiva, perceptiva y representativa en la relación entre los seres humanos y el medio ambiente es altamente reconocida como un participante importante en la comprensión del compromiso ambiental. Un entorno con espacios verdes cataliza una mayor interacción entre los seres humanos y la naturaleza. El tema de las áreas verdes es complejo, permitiendo diferentes perspectivas y perspectivas de análisis. En este estudio se buscó enfatizar y reflexionar sobre los beneficios para la salud que brindan las áreas verdes en el espacio escolar y sus aportes a la calidad de vida de la población estudiantil. El objetivo principal del estudio fue verificar los beneficios que aportan los espacios verdes insertados en los ambientes escolares para el sistema educativo, el bienestar y la salud de los estudiantes. La metodología se llevó a cabo mediante análisis observacional y estructuras y organización de espacios en cuatro escuelas (dos centrales y dos periféricas) en João Pessoa (PB). En estos lugares se observó si existía una composición florística así como su aproximación con los estudiantes. En el ámbito educativo, estos espacios son fundamentales para las prácticas docentes, contribuyendo a la calidad de vida de los estudiantes. Constatou-se que as escolas centrais apresentam poucos espaços verdes, remetendo-se em poucas árvores, jardins e arbustos, se comparado com escolas mais periféricas, com uma organização florística maior, sustentável e contato direto com os estudantes, visualizando uma melhoria no desempenho escolar e bem-estar humano. Destacamos que a natureza precisa estar presente na organização espacial e/ou no cotidiano das escolas, pois é compreendida como um espaço potencial para o desenvolvimento equilibrado dos estudantes. Esses espaços precisam ser mais trabalhados, pois representam um recurso grandioso para a socialização e melhoria na qualidade de vida, além de possibilitar melhor desempenho nos estudantes. Por desempenharem diferentes funções as áreas verdes proporcionam inúmeros benefícios tanto para a qualidade do meio ambiente trazendo um equilíbrio ambiental, quanto para saúde e bem-estar no ambiente educacional. Estudos que investiguem a relação de áreas verdes e saúde em centros urbanos em especial os ambientes educacionais são extremamente necessários, e podem contribuir na formação de políticas públicas que norteiem práticas sustentáveis e de melhorias na condição da saúde da população.

Palabras-chave: Áreas verdes. Calidad de vida. Salud, ambiente escolar. 


\section{Introdução}

O s problemas relacionados as condições do meio ambiente têm sido percebidos com maior intensidade em áreas urbanas, portanto, pesquisas relacionadas com a qualidade do ambiente urbano podem contribuir na melhoria e no planejamento a partir da geração de políticas públicas capazes de tornar o uso e a ocupação dos espaços nas cidades menos impactantes ao meio ambiente, e melhorar a qualidade de vida dos cidadãos, que necessitam de um ambiente ecologicamente equilibrado e sustentável.

Com isso, o contato com espaços e elementos naturais é importante para a formação humana. 0 ambiente com áreas verdes, possibilita maior conexão entre humanos com a natureza. Portanto, essas áreas são importantes principalmente em espaços urbanizado para o bem-estar humano, valorização e embelezamento dos locais, além de desempenharem papel funcional, sustentável e na qualidade de saúde (MASCARÓ, 2010).

Diversos pesquisadores apontam que mesmo pequenos espaços naturais (áreas verdes) em áreas urbanas, afetam positivamente seus usuários. Num estudo realizado, Kaplan e Kaplan (1989) defendem que o ambiente natural é influente, as vivências nestes locais possibilitam uma experiência restauradora quando relacionadas ao estado emocional como, por exemplo, a fadiga mental (estresse). Estas descobertas estão associadas aos resultados de pesquisas que tratam da cognição humana, tornando as pessoas mais ativas e criativas (ULRICH, 1993).

Trazendo essas situações para um contexto educacional vemos grande aplicabilidade nos espaços internos e externos dos estabelecimentos de ensino. Nesse sentido a melhoria da qualidade dos pátios escolares constitui-se numa importante alternativa em tornar esses ambientes, locais mais atrativos e prazerosos. A vegetação bem planejada é um dos elementos que mais colabora para melhorar a qualidade destes espaços, agregando valores estéticos, melhorando suas condições de conforto térmico melhorando a qualidade da saúde.

Nos últimos anos, constata-se que, o interesse pelos pátios escolares tem crescido significativamente, principalmente em escolas mais urbanizadas e centrais. Isso pode estar relacionado com problemas de espaços disponíveis para brincar nos centros urbanos, para a permanência dos estudantes e, também, com o aumento da criminalidade em parques e praças públicas.

O contato com a natureza no espaço escolar pode ter influência benéfica para todo o sistema educacional como um recurso de conhecimento e em questões para a melhoria da qualidade de vida e saúde. Como isso, esses ambientes de áreas verdes contribuem além do desempenho escolar a melhoria no convívio social.

Numa perspectiva de saúde pública, a convivência nesses locais com áreas verdes pode promover a melhoria na qualidade de vida com a redução de doenças e equilíbrio na condição fisiológica humana, contribuindo assim na redução de atendimentos em estabelecimentos de saúde pública.

Este estudo desenvolveu-se com o objetivo de verificar os benefícios que os espaços verdes inseridos nos ambientes escolares contribuem para o sistema educacional, o bem-estar e saúde dos estudantes.

\section{DESENVOLVIMENTO TEÓRICO}

\section{$2.1 O$ QUE ENTENDEMOS POR ÁREAS VERDES?}

As áreas verdes são caracterizadas pela continuidade e predominância da cobertura vegetal, com características regionais, que se distingue da arborização como apenas um elemento acessório, típico em canteiros centrais de avenidas (ARFELLI, 2004). Encontramos espaços verdes em praças, jardins, parques urbanos, estes, muitas vezes, utilizados pela população como espaços livres para práticas esportivas e lazer. Além de servirem como equilíbrio no espaço urbano e de locais de lazer, também podem oferecer um colorido e plasticidade ao meio urbano.

Para Llardent (1982, p. 151) as áreas urbanas estão organizadas nas seguintes três categorias: Sistemas de espaços livres, como um conjunto de espaços urbanos ao ar livre destinados ao pedestre para o descanso, o passeio, a prática de atividades esportivas e, em geral, o recreio e entretenimento; Espaço livre, como, quaisquer das distintas áreas 
verdes que formam o sistema de espaços livres; Zonas verdes, espaços verdes, áreas verdes, equipamento verde, caracteriza-se por qualquer espaço livre com predominância das áreas plantadas de vegetação, correspondendo, em geral, ao que se conhece como parques, jardins ou praças.

Outras definições para espaços livres e áreas verdes, são elaboradas por Lima et al. (1994, p. 545) como: Espaço livre, um conceito mais abrangente, que integra os demais, em contraposição aos espaços construídos inseridos nas áreas urbanas; Áreas verdes, são locais onde há a predominância de vegetação arbórea, que englobam as praças, os jardins públicos e os parques urbanos. Este autor também considera os seguintes tipos de áreas verdes:

Parque urbano - Enquadra-se como uma área verde, com função ecológica, estética e de lazer, no entanto com uma extensão maior que as praças e jardins públicos. Praça - Enquadra-se como um espaço livre público cuja principal função é o lazer. Quando não existe a vegetação e a mesma se encontra impermeabilizada não é considerada uma área verde. Arborização urbana - Representa elementos vegetais de porte arbóreo dentro da cidade. Nesse enfoque, as árvores plantadas em calçadas fazem parte da arborização urbana, porém não integram o sistema de áreas verdes (LIMA et al., 1994, p. 545).

Em questões conceituais o Ministério do Meio Ambiente (1999) considera "áreas verdes", em especial os espaços urbanos, como o conjunto de "áreas intraurbanas que apresentam cobertura vegetal, arbórea (nativa e/ou introduzida pelo ser humano ou animais), arbustiva ou rasteira (gramíneas) e que tem grande contribuição para a qualidade de vida e o equilíbrio do ambiente urbano", Lima e Amorim (2006, p. 2) afirmam que as áreas verdes assumem um papel muito importante no ambiente urbanizado quanto à qualidade do ambiente, servindo de equilíbrio entre a vida urbana e o meio ambiente quando esse espaço tem seu uso sustentável.

São inúmeros os benefícios que as áreas verdes promovem no ambiente, e suas reduções têm sido associadas à alteração de características do meio físico, como o descontrole do microclima local. Essas mudanças podem afetar diretamente a composição da fauna de vetores responsáveis por doenças infecciosas possibilitando o aumento de insetos e animais que possam transmitir diversos tipos de doenças como exemplos: dengue e febre amarela (LOURENÇO, 2016).

Reforçando a importância dessas áreas nos ambientes urbanizados, Barreto; Silva; Souza, (2016 p. 6) apresentam diversas funções benéficas e vitais como:

Função ecológica, quando esses ambientes naturais minimizam os impactos decorrentes da industrialização e urbanização, como as ilhas de calor urbanas e o aquecimento global; Função estética, ambientes associados a harmonização na integração entre os elementos naturais das áreas verdes e os espaços construídos e os destinados à circulação, proporcionando sensações de bem estar na população; Função social, quando a área verde está diretamente associada à oferta de espaços para sociabilização e o lazer da população, essenciais à qualidade de vida, saúde e bem estar da população.

Essas áreas verdes possuem inúmeros benefícios, tanto ecossistêmicos como de qualidade de vida. Em relação aos benefícios ecossistêmicos podemos citar a diminuição de temperaturas (OLIVEIRA, et al., 2011) resultando em diminuição de ilhas de calor (SOLECKI, et al., 2005).

Relativamente a esta questão de benefícios e valores dos ambientes verdes, Biondi (2000, p. 45) classificaos em valores como:

a) Valores estéticos - relacionados principalmente aos benefícios visuais fornecidos pelas plantas, proporcionando um contato básico do homem com a natureza; b) Valores ecológicos - incluem os benefícios de melhoria microclimática, amenização da poluição atmosférica e acústica, e proteção do solo e da fauna; destacando-se o papel das árvores na qualidade de vida em ambientes urbanos; c) Valores físicos e psíquicos do homem - os físicos estão relacionados ao conforto proporcionado pelas árvores, com a alteração do microclima urbano (temperatura, vento, umidade, insolação e poluição atmosférica e sonora); já os psíquicos se referem a benefícios como a atenuação do estresse e o bem-estar proporcionado pelo contato do homem com a natureza; d) Valores políticos e econômicos - associados à valorização da cidade pela criação de novas áreas verdes e pelo aumento de ruas arborizadas, tendo como argumento a 
melhora da qualidade de vida urbana. Inclui também a especulação imobiliária e a valorização das propriedades próximas a parques, hortos e ruas arborizadas; e) Valores sociais - referem-se a aspectos como a oportunidade de convívio de pessoas das mais variadas classes sociais, sem distinções, e a capacidade de proporcionar educação ambiental.

Estas áreas verdes são importantes para o processo de planejamento e organização de cidades, para se obter níveis satisfatórios de qualidade de vida, pois, contribuem para o controle do clima, da ventilação, dos ruídos urbanos, redução de temperatura, purificação do ar, retenção da água no solo e controle da poluição, além de embelezar e trazer vida as cidades (MASCARÓ, 2010).

Na Figura 1: visualizamos a gama de benefícios que as áreas verdes podem promover na saúde humana e sua contribuição para o bem-estar de toda a população, reduzindo o acesso em instituições de saúde principalmente as públicas subsidiadas pelo Sistema Único de Saúde.

Figura 1: Vias de exposições em que as áreas verdes podem resultar em desfechos na saúde

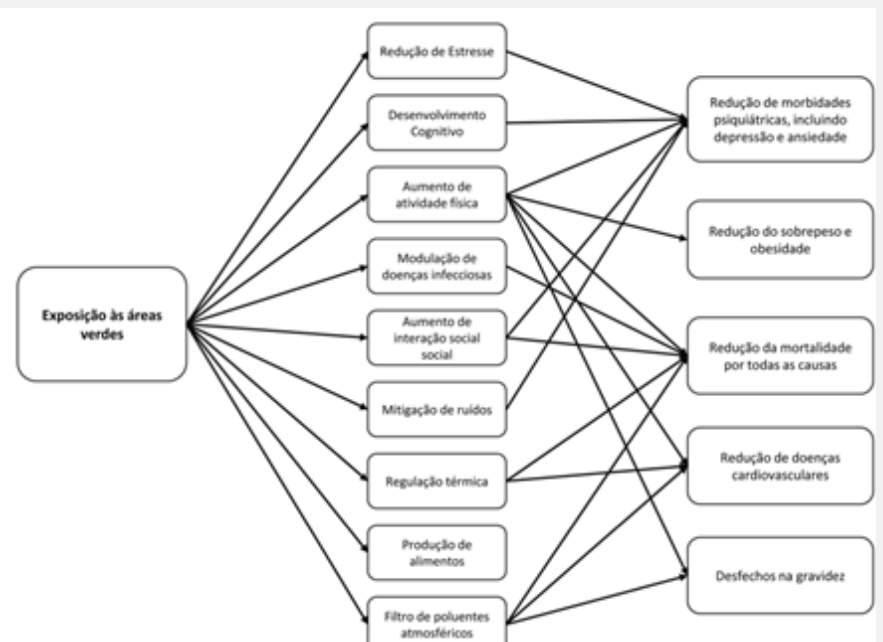

Fonte: Adaptado de James et al., 2015.

\subsection{OS ESPAÇOS VERDES NO AMBIENTE ESCOLAR}

O contato com áreas verdes prevê um aumento significativo na saúde e do bem-estar e melhoria na qualidade da saúde, independente da classe social e da idade da população residente ou próxima a estes locais. A presença de áreas verdes, além de interferir na qualidade de vida dos seres humanos, é fundamental para a diminuição dos problemas antrópicos com a urbanização e ambientais (BARGOS, 2012).

As áreas verdes, se inseridas em ambientes educacionais como em escolas, podem promover inúmeras atitudes nos alunos, principalmente, o gostar de estar no local. Estes espaços possibilitam novas experiências e contatos sociais, "quebrando" uma rotina monótona vivenciada na maioria dos espaços escolares e proporcionando um convívio socioambiental e agregando qualidade saudáveis para toda a comunidade escolar (BOECHAT; ESPINDULA, 2016).

Nesta perspectiva, quando observamos alguns espaços escolares, constatamos a ausência de "espaços verdes" ou, quando muito, verifica-se apenas a presença de locais abandonados e de difícil acesso. Assim, o local de convivência dos alunos, em muitos casos, se restringe a espaços construídos, sem vegetação. Acredita-se que, transformar esses espaços em locais de agradável convivência, é uma forma de incentivar na prática a respeitar o meio (OLIVEIRA, et al., 2016).

O contato com a natureza é essencial no processo de ensino-aprendizagem e melhorais nas condições biopsicossocial, contribuindo para que os estudantes sejam mais felizes, criativos e saudáveis e tenham qualidade de vida. Portanto, a inserção da vegetação no espaço escolar não só valoriza o ambiente esteticamente, mas faz com que os educandos, educadores e toda a comunidade escolar, tenham uma melhor qualidade e condições melhores na saúde (LOUV, 2016). As escolas com amplos jardins, árvores e plantas ou cercadas de áreas verdes podem ajudar a melhorar 0 desempenho estudantil conforme é comprovado em diversos estudos.

Os ambientes escolares, principalmente os situados nos grandes centros urbanos, os quais possuem áreas verdes, tendem a menor exposição a ruídos externos (estradas, aeroportos ou outros) que contribuem para o melhor desempenho na aprendizagem dos alunos (BOECHAT; ESPINDULA, 2016).

O mundo tecnológico e o dia a dia agitado de muitas crianças, jovens e adultos, não despertam o interesse nem disponibilizam o tempo para praticar atividades ao ar livre. Os indivíduos permanecem muito tempo em casa, no celular, na internet e 
estabelecem pouca interação social real, com isso podem trazer inúmeros problemas para saúde. A imersão nessas áreas verdes pode evitar que esses indivíduos se tornem futuramente pessoas sedentárias, tristes, insatisfeitas e depressivas (BOECHAT; ESPINDULA, 2016). Portanto, um ambiente escolar "verde" possibilita inúmeros benefícios, inclusive para suprir a falta desse contato com a natureza (LOUV, 2016).

Noutro aspecto, a arborização nas escolas é fundamental para representar a importância da vegetação no atual contexto ambiental global. Além de diversos benefícios, as árvores são o símbolo de uma natureza que durante muito tempo vem sendo destruída e a inserção delas, no espaço escolar reforça nos alunos a atenção que se deve dar às questões ambientais.

É ideal que as escolas desenvolvam programas que estejam para além do currículo ou das viagens de campo para aproximar os alunos com a natureza. Consequentemente, deve-se promover no projeto físico da escola, espaços para brincar que incorporem a natureza (LOUV, 2016).

Neste sentido ressalta-se essa grande importância do brincar na escola, nos espaços verdes que dispõem, por meio de estudos realizados no Canadá. Os investigadores descobriram que os alunos que frequentam escolas com ambientes naturais diversificados são mais ativos fisicamente, mais conscientes em termos de nutrição, mais civilizadas socialmente e mais criativas. Portanto, reafirma-se a importância da naturalização dos terrenos escolares. Ainda nestes estudos revelou-se que áreas verdes nas escolas melhoram o aprendizado, em comparação com as áreas cimentadas e gramados, geralmente encontradas em escolas mais urbanas e esses espaços verdes, quanto mais variados para brincar, promovem a inclusão social, independentemente de género, raça, classe ou capacidade intelectual, além de serem mais seguros (LOUV, 2016).

Outro benefício apontado em pesquisa relacionada com áreas verdes em ambientes escolares é o seu impacto sobre os educadores. Os pesquisadores canadenses descobriram que os professores expressavam um entusiasmo renovado para ensinar estando próximos ou inseridos nestes espaços. Numa era do aumento de fadiga, o impacto que as escolas verdes e a educação ao ar livre têm nos profissionais não deve ser subestimado. Os professores também merecem ser expostos às qualidades restauradoras da natureza, o que irá resultar em melhorias no seu bem-estar e na saúde (LOUV, 2016).

\section{$2.1 O$ QUE ENTENDEMOS POR ÁREAS VERDES?}

De acordo com diversos pesquisadores, retratam que os espaços verdes possibilitam diversos benefícios para os seres humanos nos diversos locais que possibilitam esse contato com a natureza. Nos ambientes educacionais, os espaços verdes potenciam inúmeras possibilidades de atividades práticas e vivenciadas. Portanto, enquanto educadores/educadoras é importante tomar consciência da existência desses espaços verdes e dos efeitos que estes têm na construção dos saberes necessários ao exercício profissional, e no despertar em seus educandos, atitudes de sensibilização, preservação e proteção dos mesmos (BERRETO; SILVA; SOUZA, 2016).

A utilização dos espaços verdes nos ambientes escolares, tem demonstrado influências positivas em questões de desenvolvimento cognitivo, na memória e diminuição na desatenção em crianças com idade primária, contribuindo assim, para o desenvolvimento biopsicossocial.

Estudos demonstram que escolas com jardins, árvores e plantas contribuem para o desempenho estudantil. De acordo com um estudo realizado na Espanha por Dadvand (2015) com 2.593 alunos entre 7 e 10 anos de idade, comprovou-se que a maior intensidade de verde na escola ou imediações foi capaz de melhorar nos alunos em até $5 \%$ a capacidade de armazenar e trabalhar informações capacidade conhecida como "working memory", em um ano. Também, se verificou que as escolas que aumentam a exposição dos alunos a áreas verdes conseguem reduzir em até $9 \%$ o problema de memorização dos alunos.

Outro estudo realizado por Dadvand et al. (2014) conduziram a pesquisa com 3.178 crianças em idade escolar relatando que o aumento considerável de áreas verdes no entorno das suas residências foi associado com menor prevalência relativa de $11 \%$ a $19 \%$ no sobrepeso/obesidade e comportamento sedentário nessas crianças. 
Embora estudos não sejam conclusivos, os pesquisadores apontam que a menor exposição ao barulho do tráfego e à poluição poderia explicar o alto desempenho dos alunos inseridos em áreas mais verdes. As crianças expostas à poluição do ar ou à poluição sonora tendem a ter maior prejuízo em seu aprendizado. As escolas com mais áreas verdes ou situadas em vizinhanças mais arborizadas acabam funcionando como contraponto importante ao barulho de grandes áreas urbanas. Corroborando este estudo, Berreto, Silva e Souza (2016) escreve que a presença de espaços verdes tem sido associada ao aumento de atividades físicas que, por sua vez, estão diretamente relacionadas com melhoramento da função cognitiva em crianças e consequentemente na melhoria de taxas fisiológicas e de saúde.

Constata-se que muitas escolas dispõem de áreas verdes dentro dos limites de suas estruturas físicas ou nas adjacências, porém observa-se que poderiam ser utilizados mais estes locais. Outro fator importante a ser destacado, é a manutenção destes locais, tornando-os acessíveis e com segurança (ALVES, 2009).

Esses espaços precisam existir, ser cuidados e utilizados pelos alunos e professores em suas atividades pedagógicas de sensibilização ecológica. São inúmeros os temas que podem ser abordados usufruindo das áreas verdes, de modo a despertar as percepções e saberes nos educandos. Neste sentido, sabe-se que os alunos são os principais disseminadores de assuntos discutidos no ambiente escolar, principalmente se os assuntos forem relacionados a questões da problemática ambiental.

Enfatizando a problemática ambiental e a da difusão de informações e ações para a melhoria neste contexto, a escola é uma das principais responsáveis pela educação do ser humano. Cabe a ela transmitir conhecimentos e resgatar atitudes sobre a questão ambiental, tornando-se necessário transformá-la num ambiente de discussões teóricas, mas também onde se efetue a prática ambiental.

Sendo o Desenvolvimento Sustentável tão importante no século que nos encontramos urge que este seja abordado de uma forma assertiva junto dos

${ }^{1}$ No texto onde se refere "caderno de campo", esse, é um local de anotações onde é registrado dados da pesquisa como: data, mais jovens para que estes, para além dos indivíduos mais entendidos nesta área, também se tornem cidadãos sensibilizado para os problemas ambientais, econômicos e sociais e que com isso ajudem a resolver os dilemas que assombram a sociedade.

As escolas são de fato espaços privilegiados na implementação de atividades que promovam o Desenvolvimento Sustentável em específico seguir os objetivos propostos na Agenda 2030. A escola, no âmbito da Educação Ambiental, deve sensibilizar os alunos para o valor do ambiente e das espécies que habitam o planeta e analisar criticamente os princípios que levaram à destruição inconsequente dos recursos naturais e de várias espécies. Para além destas características ambientais, também as dimensões sociais e econômicas devem ser analisadas na escola (EFFTING, 2007).

\section{METODOLOGIA}

Esta investigação foi realizada numa abordagem qualitativa seguindo métodos de etnografia escolar, observação participante e comparativa. Foram analisadas quatro escolas públicas, municipais localizada em João Pessoa (PB), região Nordeste do Brasil (duas escolas inseridas na área urbana e duas na área periférica).

0 método utilizado consistiu basicamente de uma avaliação visual com anotações no "caderno de campo" " e ficha observacional do pesquisador, além de registros fotográficos dos elementos espaços verdes presentes nas áreas internas das escolas. Para proceder nesta avaliação, buscou-se observações a presença florística nestes espaços e suas relações de contato com os estudantes numa perspectiva de bem-estar ambiental.

Esta avaliação foi realizada levando em consideração diferentes níveis ou tipos de vegetação (quanto a quantidade e à função) que estavam presentes nos pátios das escolas. Como critérios para observação, procurou-se: a) árvores; b) arbustos; c) grama, d) local para cultivo (horta ou outro espaço dedicado ao cultivo de plantas pelos estudantes); e) canteiros

horário, desenvolvimento de atividades, ocorrências e diversos detalhes observados durante as visitas. Essas anotações servem como subsídio das discussões dos dados coletados. 
de flores e f) "ambientes sustentáveis" (com materiais reutilizados).

Desta forma, para cada escola visitada foi realizado uma visita com duração de uma hora e trinta minutos, seguindo de registros fotográfico e anotações no "caderno de campo", destacando se haviam esses componentes, sua distribuição/organização e contato com os estudantes.

\subsection{As Pesquisas Qualitativas}

A pesquisa qualitativa tem características fenomenológicas, parte da compreensão do viver e não das definições ou conceitos. É uma compreensão voltada para os significados do perceber. Ou seja, refere-se às expressões claras sobre as percepções que o sujeito tem daquilo que está sendo pesquisado, às quais se expressam pelo próprio sujeito que as percebe (MINAYO, et. al, 2010).

Em relação à pesquisa qualitativa, essa é definida como resposta às questões muito particulares dentro das Ciências Sociais, com um nível de realidade que não é quantificada em números. Esse tipo de pesquisa trabalha com as representações de significados, motivos, aspirações, crenças, percepções, opiniões, valores e atitudes (MINAYO, et. al, 2010).

Minayo et al. (2010) define a pesquisa qualitativa como universo da produção humana que se resume no mundo das representações e da intencionalidade e torna-se objeto desse mesmo tipo de pesquisa. Segundo a autora, este universo dificilmente poderá ser traduzido em números e indicadores quantitativos.

A pesquisa qualitativa pode ser definida em etapas como: (1) fase exploratória, a qual consiste na produção do projeto de pesquisa e todos os passos e procedimentos necessários para preparar a intervenção em campo; (2) trabalho de campo, consiste em levar para a prática empírica toda a construção teórica elaborada na primeira fase. Nessa etapa é a organização das observações, entrevistas ou outras formas de comunicações e interlocução com os pesquisadores, levantamento do material documental e outros; (3) análise e tratamento de material empírico e documental. Essa última fase, trata do conjunto de procedimentos para valorizar e compreender, interpretar os dados empíricos com articulações na teoria em que o projeto foi baseado com outras leituras teóricas e interpretativas advindas das informações de campo. Essa etapa pode ser subdividida em três tipos de procedimentos: a) ordenação dos dados; b) classificação dos dados; c) análise propriamente dita (MINAYO, et. al, 2010).

Considerando os vários ciclos de uma pesquisa qualitativa, constata-se na fase exploratória um dos momentos mais importantes pois, compreende várias fases da construção de uma trajetória investigativa como: a) escolha do tópico de investigação; b) delimitação do objeto; c) definição dos objetivos; d) construção do marco teórico conceitual; e) seleção dos instrumentos de construção e coleta de dados; f) exploração de campo (MINAYO, et. al, 2010, p. 38).

0 estudo de campo qualitativo não tem um significado preciso em quaisquer das áreas em que são utilizados. Para alguns pesquisadores, grande parte dos estudos de campo são necessariamente qualitativos, pois se identificam com a observação participante, análises interpretativas e pesquisas etnográficas (MINAYO, et. al, 2010).

\section{RESULTADOS E DISCUSSÃO}

\subsection{Caracterização dos "Espaços Verdes" nas escolas de João Pessoa (PB) região Nordeste - Brasil}

\subsubsection{Escola A - Central}

Em relação aos espaços verdes nesta escola, não foi observado grande quantitativo, limitando-se em poucas árvores, gramíneas e jardins. Devido ao espaço do pátio ser reduzido, visualmente é perceptivo que foi suprimido por construções de concretos. É importante destacar que no centro do pátio escolar, possui uma grande árvore a qual os estudantes utilizam como sombreamento para brincadeiras e leituras e momentos de convívio social. É notório a sensação térmica agradável nas salas de aulas próximas a esse elemento florístico se comparado com as demais salas que não tem uma composição de áreas verdes.

Nessa questão de qualidade ambiental, que os espaços verdes promovem, corroboramos com Nucci (2008), em que trata que estes espaços promovem 
uma estabilidade do solo com a fixação das raízes das plantas, além de criar obstáculos par o vento, promovem a qualidade de água, filtram o aumentam a qualidade do ar, diminuindo consideravelmente trazendo uma sensação térmica agradável.

Em um estudo realizado por Buccheri-Filho e Tonetti (2011), sobre a qualidade ambiental nas paisagens no ambiente urbano, é dito que a qualidade ambiental nesses espaços enquanto componente da qualidade de vida, pode ser definida como a ampliação de condições favoráveis do ambiente urbano, que suprem as necessidades fisiológicas e psicológicas do ser humano, como resultado, propicia a melhoria da qualidade de vida da população.

No mesmo espaço citado acima, possui um canteiro com plantas medicinais e hortaliças que foi confeccionado com professores em um projeto ambiental, no entanto nota-se que este, não está em atividade. Segundo relatos dos próprios estudantes do projeto, sentem a falta dessas atividades e o contato com os elementos naturais como a terra e as plantas. Atividades como estas são importantes para o desenvolvimento integral dos estudantes, devido ao contato direto com os elementos naturais podem promover a integração, bem-estar subjetivo e questões de melhoria na saúde devido ao contato que os elementos naturais promovem (LOUV, 2016).

Outro local agradável visualmente e funcional, é o portão de acesso principal à escola. Nesse espaço possui duas árvores de médio porte que fazem uma espécie de cobertura "um portal", para acesso as salas de aulas, corredores e setores educacionais, possibilitando uma sensação térmica favorável a condição local, além do embelezamento do local. Nessa questão de condicionantes térmicos, Nucci (2008) afirma que há melhorias e equilíbrio na umidade do ar, consequentemente proporcionando condições para a inalação do ar.

Nessas perspectivas de benefícios dos espaços verdes e o contato com esses, estudos corroboram positivamente em relação a longevidade, doenças cardiovasculares, obesidade, saúde mental, qualidade do sono, recuperação de doenças e desfechos de natalidade. Grande parte desses estudos concentram-se na união europeia ou norteamericana. Nesses países, os efeitos mais apreciados são observados em áreas urbanas e em classes socioeconômicas mais baixas, nesse sentido se houver melhorias no ambiente, consequentemente diminuirão o acesso ao atendimento de saúde (LOURENÇO, et. al. 2016).

Constatou-se alguns jardins pequenos com poucas plantas e flores, mas em contato direto com os estudantes, principalmente em intervalos e atividades recreativas.

\subsubsection{Escola B - Central}

Nessa escola não foi observado espaços verdes significativos quantitativamente. Todo o espaço interno, o pátio escolar é suprimido por concreto bruto ou com cerâmica. Os estudantes utilizam esses espaços concretados dispondo de poucas coberturas, para suas interações nos intervalos e atividades desenvolvidas pelos professores.

O único elemento verde, nesse espaço, e de contato com os estudantes é uma árvore de porte pequeno e alguns vasos com plantas. É notório a sensação térmica desagradável nas salas de aula devido ao calor e a falta de espaços verdes que poderiam melhorar essa condição térmica, essas condições podem interferir negativamente no desempenho educacional e diminuindo a qualidade de vida dos estudantes.

Conforme Lourenço (2016) é necessário os espaços verdes, principalmente nos ambientes educacionais, pois comprova-se que esses ambientes naturais promovem a diminuição do estresse/aumento do relaxamento, contatos sociais, diminuição da temperatura e ruídos, aumento da umidade e captura de material particulado certamente têm uma influência nos efeitos fisiológicos protetores dos ambientes verdes, nesses sentido os alunos próximos a áreas verdes podem melhorar o rendimento educacional e na qualidade de vida.

Tais apontamentos revelam os benefícios que as áreas verdes em ambientes públicos em especial os educacionais, podem promover à saúde e ao bemestar dos indivíduos. Nesse sentido, a construção de novas áreas verdes, a revitalização das existentes, ou mesmo, a conservação e preservação da vegetação presente no espaço urbanizado, deve ser percebido pelos gestores públicos como benefício futuro a toda população (PEREHOUSKEI; DE ANGELIS, 2012). A importância destas áreas deve ser considerada principalmente no planejamento da cidade e adequações de espaços já existentes, 
visando as vantagens de todas as possibilidades ecológicas (PEREHOUSKEI; DE ANGELIS, 2012), estéticas e sociais, e assim contribuir, tanto para qualidade ambiental no ambiente urbano, quanto para a qualidade de vida da população.

\subsubsection{Escola C - Periférica}

Quanto aos espaços verdes na escola, foi observado uma quantidade expressiva de árvores, arbustos e canteiros com folhagens ornamentais e algumas flores. Durante as observações foi possível constatar as interações entre os usuários (alunos, professores e funcionários) no pátio e a vegetação existente, principalmente através de áreas com sombreamentos e refúgio para dias mais quentes.

Plenamente integradas à vegetação arbórea, podese encontrar diversas espécies de plantas arbustivas e forrações, muitas das quais apresentando diversos jardins com flores. Estas espécies dão um toque de cor no pátio além de interagirem de diversas formas com os alunos, servindo de material didático ou incentivando a criatividade e a realização de brincadeiras e projetos ambientais.

Nos espaços comuns aos alunos é perceptível um pátio suprimido por construções de concretos, porém em diversos pontos encontra-se jardins com plantas ornamentais.

Outro espaço agradável visualmente e funcional, é o portão principal de entrada na escola. Ao chegar, atrás dos muros, possui árvores grandes, que servem como uma cobertura verde, para acesso as salas administrativas, corredores e setores educacionais. É possível constatar que na entrada lateral e de acesso dos alunos, possui plantas nos corredores. É notório a sensação térmica agradável nesse espaço.

Pode-se observar e segundo relatos dos alunos, esses espaços verdes, são mantidos pelos funcionários da escola e em atividades com os alunos. Esta mesma escola, possui uma área grande com horta, porém no período da visita não estava em funcionamento. Segundo relatos dos professores e da direção, este espaço era utilizado pelos alunos em projetos de Educação Ambiental.

No espaço posterior a escola, possui uma grande área com plantas frutíferas, bananeiras e arbustos que eram utilizados em atividades com os alunos. Os ambientes que possuem espaços como esses, promovem melhor interação entre os estudantes conectando-os com os elementos naturais e melhorando suas condições de saúde (LOUV, 2016).

\subsubsection{Escola D - Periférica}

A escola dispõe de vários espaços verdes, com árvores frutíferas (goiabeiras, mangueiras e cajueiros), arbustos e canteiros com folhagens ornamentais e algumas flores. Durante as observações foi possível constatar as interações entre a comunidade escolar no pátio e a vegetação existente, principalmente na área sombreada, junto aos pés dos cajueiros (em uma das observações, alguns alunos estavam em cima do pé colhendo caju).

Outro espaço agradável visualmente e funcional, é a área frontal, entrada principal da escola. Possui um belo jardim com inúmeras plantas, árvores, servindo como uma cobertura vegetal, para acesso aos setores educacionais. É notório a sensação térmica agradável nesse espaço, devido as plantas que estão nesse local.

A escola desenvolvia projetos ambientais como construção e manutenção de uma horta, ao lado da escola e cuidados nos jardins que eram auxiliados pelos alunos. Durante as observações e relatos da direção a horta, foi desativada, pois, o professor que desenvolvia o projeto não está mais no quadro docente da escola.

No espaço posterior a escola, possui uma grande área, mesmo, mesmo local possui a quadra de esporte coberta. Constata nesse local, um grande número de resíduos dispostos no chão, são papéis, plásticos, garrafas e embalagens Tetra Park.

Outro pondo a ser destacado, é, o "natural" com diversas árvores e gramíneas, que é possível possibilitando observar na parte posterior da escola, essa visão possibilita a (re) conexão dos alunos como - meio ambiente de maneira reflexiva, sensibilizando-os para a conservação e preservação, afirmando a importância dos espaços verdes no ambiente escolar para o ensino-aprendizagem (LOUV, 2016).

Pode-se observar o pátio dessas escolas, onde há presença de algumas árvores. No entanto, estas árvores estão localizadas em apenas uma pequena 
porção do pátio, enquanto o restante da área é marcado pela ausência de vegetação.

Vale ressaltar neste texto, que no dia da observação, um dos alunos subiu ao cajueiro para retirar o fruto. Neste sentido, demonstra-se a importância e necessidade de mais árvores e vegetação nestas áreas para a conexão das crianças como o meio natural. Essa conexão com o natural é de suma importância para o desenvolvimento psicossocial dos estudantes (LOUV, 2016; PROFICE, 2016).

Verifica-se nestas escolas uma diversidade de árvores que desempenham um papel importante ao projetarem sombra para o refúgio nos dias quentes e áreas de lazer e brincadeira para as crianças. Algumas destas árvores são frutíferas servindo de atrativo para as crianças e para muitos pássaros que frequentam o pátio, neste sentido conectando os alunos com a natureza.

Representa o corredor de acesso dos alunos à parte interna da escola. Verificam-se, algumas plantas ornamentais distribuídas nos canteiros. Esses tipos de espaços, estão distribuídos em diversos pontos do pátio desta escola, alguns sendo mantidos e cuidados pelos alunos. Esta mesma escola, possui uma área com horta, porém no período da visita não estava em funcionamento. Segundo relatos dos professores e da direção, este espaço era utilizado pelos alunos em projetos de EA, porque a escola fazia parte de um programa com recursos federais.

\section{CONSIDERAÇÕES FINAIS}

Os pátios das duas escolas situado em bairros mais distantes da região central, diferem dos pátios das duas escolas centrais, principalmente pela presença significativa de áreas verdes. Observou-se a presença de árvores nos pátios destas escolas, no entanto, apresentam-se, ainda em pequenas quantidades, de forma muito esparsa e, frequentemente, mal distribuídas em relação às áreas de contato mais comum entre os estudantes. Mesmo assim, nestas escolas, já se pode observar interações entre os usuários (alunos, professores e funcionários) no pátio e a vegetação existente, principalmente através de áreas com sombreamentos e refúgio para dias mais quentes.

Destacamos que a natureza e estas áreas verdes, precisam estar presentes na organização espacial e/ou no cotidiano das escolas, pois é compreendida como um espaço com potencialidade para o desenvolvimento educacional e social dos estudantes. Esses espaços precisam ser mais trabalhados, poi representam um recurso significativo para a Educação Ambiental. Por outro lado, são uma forma de aproximar os alunos da natureza melhorando a qualidade de vida, saúde e promovendo o lazer através do contato direto com a natureza.

Levando-se em consideração os aspectos expressos ao longo do texto, considera-se que áreas verdes são essenciais no processo de crescimento e aprendizagem dos educandos. Os espaços verdes, quando em ambientes escolares, incentivam o ensino, a práticas esportivas, brincadeiras espontâneas ao ar livre, a boa alimentação, além de trazer bem-estar e contribuir para a saúde dos alunos. Além da saúde, embelezam e trazem "vida" ao local em que estão inseridas.

É necessário que se integrem mais áreas verdes em espaços escolares, especialmente nas áreas mais urbanizadas. 0 contato com espaços verdes faz com que a criança cresça respeitando a natureza, aprenda a importância da sustentabilidade para o futuro do planeta e se torne um cidadão responsável. As duas escolas nas áreas centrais que foram visitadas possuem bastante variância quanto às formas e tamanhos de seus pátios, no entanto apresentam como característica comum paisagens bastante desoladoras e a presença muito escassa de vegetação (quando não ocorre a sua total ausência).

É comum encontrar nos pátios dessas escolas, situadas nas áreas mais centrais das cidades, a predominância quase total de áreas pavimentadas ou revestidas com cerâmicas e/ou concreto bruto. Raramente é encontrada alguma parcela da superfície revestida por vegetação rasteira como gramíneas ou plantas de baixo porte.

Em relação aos espaços das escolas periféricas, em geral são muito pouco atrativos visualmente, oferecendo diversos elementos ou oportunidades para que os alunos brinquem, interajam e vivenciem, além dos docentes desenvolvam atividades de recreação e que possibilitem a melhoria na saúde ambiental dos estudantes. Além disso, as áreas verdes encontradas nessas escolas apresentam excelentes condições de conforto térmico devido à presença de várias áreas sombreadas, diminuindo o 
aquecimento que é um dos fatores qye contribuem para os problemas e diminuição do bem-estar dos estudantes e demais pessoas que utilizam desses espaços.

Estudos que investiguem a relação de áreas verdes e saúde em centros urbanos em especial os ambientes educacionais são extremamente necessários, e podem contribuir na formação de políticas públicas que norteiem práticas sustentáveis e de melhorias na condição da saúde da população.

\section{REFERÊNCIAS}

ALVES, O. Discutindo Paisagismo na Escola Estadual Tomaz Edison de A. Vieira. Artigo PDE, Maringá (2009). Disponível em: http://www.diaadiaeducacao.pr.gov.br/portals /cadernospde/pdebusca/producoes_pde/2009_ uem_geografia_md_orlanda_camargo_alves.pdf - Acesso: 20 de mai. 2019. Acesso em: 18 de mar. 2021.

ARFELLI, A. C. Áreas verdes e de lazer: considerações para sua compreensão e definição na atividade urbanística de parcelamento do solo. Revista de Direito Ambiental, São Paulo, v. 9, n. 33, 2004, p. 33-51.

BARGOS, D. C. Mapeamento e análise de áreas verdes urbanas em Paulínia (SP): Estudo com a aplicação de geotecnologias. Soc. \& Nat. v. 24, n. 1, 2012, p. 143-156.

BIONDI, D. Curso de Arborização Urbana. Curitiba-PR: UFPR, 2000.

BERRETO, A. de L. SILVA, P. D. da; SOUZA, F. R. $\mathrm{S}$. de, Áreas Verdes como espaços de aprendizagens para o ensino de Ciências na formação do Pedagogo. 2016. Disponível em: https://editorarealize.com.br/revistas/cintedi /trabalhos/23102016233225.pdf. Acesso em: 15 de jun. 2021.
BRASIL, Ministério do Meio Ambiente. Ministério da Educação. Programa nacional de educação ambiental. Lei n 9.795/99 - Cap. I. Art. 1, 2. 1999.

BOECHAT, S. L., ESPINDULA, L. Escola Parque Áreas Verdes e unidades escolares. II Seminário Científico da FACIG, I Jornada de Iniciação Científica da FACIG, 2016.

BUCCHERI-FILHO, A. T.; TONETTI, E. L. Qualidade ambiental nas paisagens urbanizadas. Revista Geografar. Curitiba: UFPR, v.6, n.1, 2011, p.23-54.

DADVANDA, $\mathrm{P}$, et al. Green spaces and cognitive development in primary school children: PNAS Early Edition, 2015.

DADVAND, P. et al. Risks and benefits of green spaces for children: a cross-sectional study of associations with sedentary behavior, obesity, asthma, and allergy. Environmental Health Perspectives, v.122, 2014, p.1329-35.

EFFITING, T. R. Educação Ambiental nas Escolas Públicas: realidade e desafios. Marechal Cândido Rondon: Centro de Ciências Agrárias, Universidade Estadual do Oeste do Paraná, 2007.

JAMES, P. et al. A review of the health benefits of greenness. Current Epidemiology Reports, v.2, 2015, p.131-42.

KAPLAN, R.; KAPLAN, S. The experience of Nature. Cambridge University Press: New York. 1989.

LIMA, V., AMORIM, M. A importância das áreas verdes para a qualidade ambiental das cidades. Revista Formação, v. 13, 2006, p. 139-165. Disponível em: http://revista.fct.unesp.br/index.php/formcao 
/arcle/viewFile/835/849. Acesso em: 18 de mar. 2019.

LIMA, A. M. L. P., et al. Problemas de utilização na conceituação de termos como espaços livres, áreas verdes e correlatos. In: Congresso de Arborização Urbana. São Luís, MA Anais São Luís: SBAU, 1994, p. 539-553.

LOURENÇO, et. al, Metrópole, cobertura vegetal, áreas verdes e saúde. Estudos Avançados, v. 30 n. 86, 2016. Disponível em: http://www.scielo.br/pdf/ea/v30n86/01034014-ea-30-86-00113.pdf. Acesso em: $10 \mathrm{de} \mathrm{fev.}$ 2021.

LOUV, R. A última criança na natureza resgatando nossas crianças do transtorno de déficit de natureza. 1 ed. São Paulo. Ed. Aquariana, 2016.

LLARDENT, L. R. A. Zonas verdes y espaços livres en la ciudad. Madrid: Closas Orcoyen. 1982.

MASCARÓ, J. L., MASCARÓ, L. Vegetação urbana. 3. ed. Porto Alegre: Masquatro, 2010.

MINAYO, M. C. de S.; DESLANDES, S. F.; CRUZ NETO, O.; GOMES, R. Pesquisa social: teoria, método e criatividade. 25. ed. Petrópolis-RJ: Vozes, 2007.
NUCCl, J. C. Qualidade ambiental e adensamento urbano: um estudo de ecologia e planejamento da paisagem aplicado ao distrito de Santa Cecilia (MSP). 2. ed. Curitiba: 0 autor, 2008, p. 150.

OLIVEIRA, M. B. dos S., et. al. Áreas Verdes escolares: possibilidades para a Educação Ambiental. Ciências em Foco. v. 9, n. 2, 2016, p. 61-71.

OLIVEIRA, S.; ANDRADE, H.; VAZ, T. The cooling effect of green spaces as a contribution to the mitigation of urban heat: A case study in Lisbon. Building and Environment, v. 46, n. 11, 2011, p. 2186-94.

PEREHOUSKEI, N. A.; DE ANGELIS, B. L. D. Áreas Verdes e Saúde: paradigmas e experiências. Diálogos \& Saberes, Mandaguari, v. 8, n. 1, 2012, p. 55-77.

PROFICE, C. As crianças e a natureza: reconectar é preciso. 1 ed. São Paulo: PandorgA, 2016.

SOLECKI, W. D. et al. Mitigation of the heat island effect in urban New Jersey. Global Environmental Change Part B: Environmental Hazards, v.6, n.1, 2005, p.39-49.

ULRICH, R.S. Biophilia, Biophobia, and Natural Landscapes. In S. R. KELLERT; E. O. WILSON (Eds). The Biophilia Hypothesis. Island Press. Shearwater Books: Washington DC. 1993. 